\title{
Outcomes of inpatient psychological treatments for children and adolescents with eating disorders at time of discharge: a systematic review
}

\author{
Leanna Isserlin ${ }^{1,2^{*}}$ (1), Wendy Spettigue ${ }^{1,2}$, Mark Norris ${ }^{2,3}$ and Jennifer Couturier ${ }^{4}$
}

\begin{abstract}
Background: Recommended first line treatment for children and adolescent eating disorders is outpatient therapy. However, a significant number of children and adolescents with eating disorders continue to require inpatient treatment during the course of their illness. The effect of psychological treatments in an inpatient setting on outcomes at the time of discharge remains unclear. This paper presents the results of a review of the literature on outcomes at the time of discharge following inpatient psychological treatment for children and adolescents with eating disorders.

Main body: The majority of studies found were observational and of low quality. The most consistently reported positive outcome of inpatient treatment is weight gain. Results related to symptom change and motivation vary between studies. Within the inpatient setting, there is considerable heterogeneity in the types of treatments offered, goals of treatment, length of stay and outcomes measured.

Conclusion: There remains a paucity of high-quality studies examining the effect of psychological treatments provided to children and adolescents in an inpatient setting. The significant heterogeneity between studies makes it not possible to compare across studies. Future research should aim to resolve these deficiencies in order to better determine the specific factors that contribute to positive outcomes of inpatient treatment for children and adolescents with eating disorders.
\end{abstract}

Keywords: Child, Adolescent, Humans, Inpatients, Hospitalization, Feeding and eating disorders

\section{Plain English summary}

For children and adolescents with eating disorders, outpatient treatment is the type of treatment with the most support in the scientific literature and should be the basis of most treatment plans. However, many children and adolescents will require inpatient treatment at some

\footnotetext{
* Correspondence: lisserlin@cheo.on.ca

'Department of Psychiatry, Children's Hospital of Eastern Ontario, University of Ottawa, Ottawa, ON K1H 8L1, Canada

${ }^{2}$ Children's Hospital of Eastern Ontario Research Institute, Ottawa, ON K1H 8L1, Canada

Full list of author information is available at the end of the article
}

point in their illness. The effect of inpatient treatment on eating disorder symptoms remains unclear. This paper aims to review the available literature on psychological treatments provided to children and adolescents with eating disorders in an inpatient setting in order to understand what is known to date. Unfortunately, there remain very few studies designed in such a way to be able to answer the question 'what is the best psychological treatment to provide in an inpatient setting to children and adolescents with eating disorders?' and due to considerable variability in the studies available, the

(c) The Author(s). 2020 Open Access This article is licensed under a Creative Commons Attribution 4.0 International License, which permits use, sharing, adaptation, distribution and reproduction in any medium or format, as long as you give appropriate credit to the original author(s) and the source, provide a link to the Creative Commons licence, and indicate if changes were made. The images or other third party material in this article are included in the article's Creative Commons licence, unless indicated otherwise in a credit line to the material. If material is not included in the article's Creative Commons licence and your intended use is not permitted by statutory regulation or exceeds the permitted use, you will need to obtain permission directly from the copyright holder. To view a copy of this licence, visit http://creativecommons.org/licenses/by/4.0/ The Creative Commons Public Domain Dedication waiver (http://creativecommons.org/publicdomain/zero/1.0/) applies to the data made available in this article, unless otherwise stated in a credit line to the data. 
only consistent positive result in the studies available is that inpatient treatment is effective in producing weight gain. Further research is needed in order to optimize treatment for children and adolescents with eating disorders in the inpatient setting.

\section{Background}

Eating disorders (EDs) are complex disorders that typically appear during childhood and adolescence [1]. Current ED guidelines and expert consensus support outpatient familybased treatment as the first-line recommended treatment for children and adolescents [2-4]. Despite this recommendation, a proportion of patients with potentially lifethreatening severe EDs will require higher levels of support, including inpatient stabilization and treatment [5].

Unfortunately, inpatient lengths of stay (LOS) for ED treatment tend to be long in comparison to other medical and psychiatric disorders, with the average LOS in studies from Germany, Japan, Switzerland and Scotland being greater than 7 weeks [6-9]. Modifying factors for LOS in adolescent patients include treatment under the Mental Health Act and nasogastric feeding, both of which appear to be associated with longer LOS [9]. Prolonged LOS is concerning, as it can disrupt adolescent development and engagement in school, family and social life. Further, inpatient treatment is expensive in terms of economic costs and intensive medical resource requirement [10]. In 2013, a review of admissions with a mean length of stay 37.9 days (standard deviation [SD] 19.7 days) to a Canadian tertiary care center for medical stabilization and initial weight rehabilitation for adolescents with AN found that the mean total hospital cost was \$51,349 Canadian Dollars (CAD) (SD \$26598) with a mean total societal cost of $\$ 54,932$ CAD (SD \$27864) per admission [10]. Similar studies from Portugal and Germany found comparable high costs for eating disorders treatment, in that the average cost per admission in those countries was 5202 to $5883 €$ and $13,367 €$ respectively $[11,12]$.

While three recently published studies examining outcomes across varying treatment settings supports the least intensive management as first line treatment for EDs [13-15], the evidence base that examines best practice for patients who do require inpatient treatment remains scant. The goal of this review is to further explore the scope and benefits of psychological treatments provided to children and adolescents with EDs in inpatient settings at the time of hospital discharge.

\section{Methods}

PRISMA systematic review methodology was used to capture all articles on inpatient treatment for EDs in children and adolescents [16]. Our search utilized the following databases: Medline, PsycINFO, EMBASE,
Cochrane Database of Systematic Reviews, Cochrane Central Register of Controlled Trials (CENTRAL) and CINAHL, and included the following search terms: Anorexia Nervosa (AN) OR Bulimia Nervosa (BN) OR Binge Eating Disorder (BED) OR Other Specified Feeding and Eating Disorder (OSFED) OR Eating Disorder Not Otherwise Specified (EDNOS) OR Avoidant/Restrictive Food Intake Disorder (ARFID) AND Inpatient Treatment. The search string was developed further and was modified for each database as appropriate (see Additional file 1). Inpatient treatment was defined for the purposes of this review as treatment that involves $24 \mathrm{~h} /$ day care in a hospital setting. Reference lists were reviewed for any additional articles. Two reviewers had to agree for inclusion of articles in our review, with a third reviewer resolving any disputes. The initial database search included all years up until March 2017. In November 2018 a forward citation chaining process was completed to search each included article to examine if it had been cited by any additional articles since March 2017 up until November 2018. Newly found articles were then screened to decide whether they matched the inclusion criteria. The forward chaining process involved the use of Google Scholar to locate all articles citing our included articles from the primary search. Inclusion criteria included original peer-reviewed research articles that focused on children and adolescents up to age 18 years, provided a description of an ED-specific treatment as well as weight and/or psychological outcomes at the time of discharge, and were published in English or French. Studies of all different types of methodology were included (randomized controlled trials [RCTs], open trials, case reports). Studies were excluded if they did not distinguish between outcomes for children and adolescents and outcomes for adults, or if they focused only on medical interventions, pharmacotherapy or refeeding protocols aimed at restoring medical stability to facilitate discharge to outpatient treatment.

For each included study, the study type (e.g. prospective or randomised control trial), number of participants included in the analysis, treatment method, primary outcome variable(s), and observed results were summarized.

Given the low quality of the studies, quantitative analysis was not possible. Qualitative review of all included studies was performed, summarizing the outcomes at end of inpatient treatment. We distinguish outcomes across various types of treatment frameworks as well as the evidence supporting the use of adjunctive therapies as part of inpatient treatment.

Two reviewers (LI and JC) independently assessed the risk for bias in the articles using the GRADE (Grading of Recommendations, Assessment, Development and Evaluations) system [17]. The GRADE system incorporates 
analysis of risk of bias based on various limitations of the studies, including lack of concealment of allocation, blinding, accounting of all participants, and selective reporting of outcomes for RCTs, and lack of an adequate control population, flawed measurement of outcomes, failure to adequately control for confounding factors and incomplete or inadequately short follow-up for observational studies.

\section{Results}

The database search initially provided $n=7136$ citations, as reported in the PRISMA flowchart (Fig. 1). An additional 49 citations were added through review of references and forward citation chaining. After removing duplicates, $n=6426$ records remained, of which $n=5881$ were eliminated given that they did not meet the inclusion criteria. Of the 545 full text articles assessed for eligibility, $n=479$ studies were excluded because they were longitudinal follow-up studies with no information on outcome at the time of discharge, were primarily adult studies, were review or secondary analysis papers, book chapters or guidelines, or did not provide sufficient description of the treatment provided, did not focus on inpatient treatment, or otherwise did not meet the inclusion criteria. Ultimately, $n=66$ studies were selected for inclusion in this review (See Fig. 1). Quantitative analysis of the results was not possible due to the varying outcome measures used, the low quality of the studies and the high heterogeneity in methods used amongst the studies. Instead a narrative summary of the results is
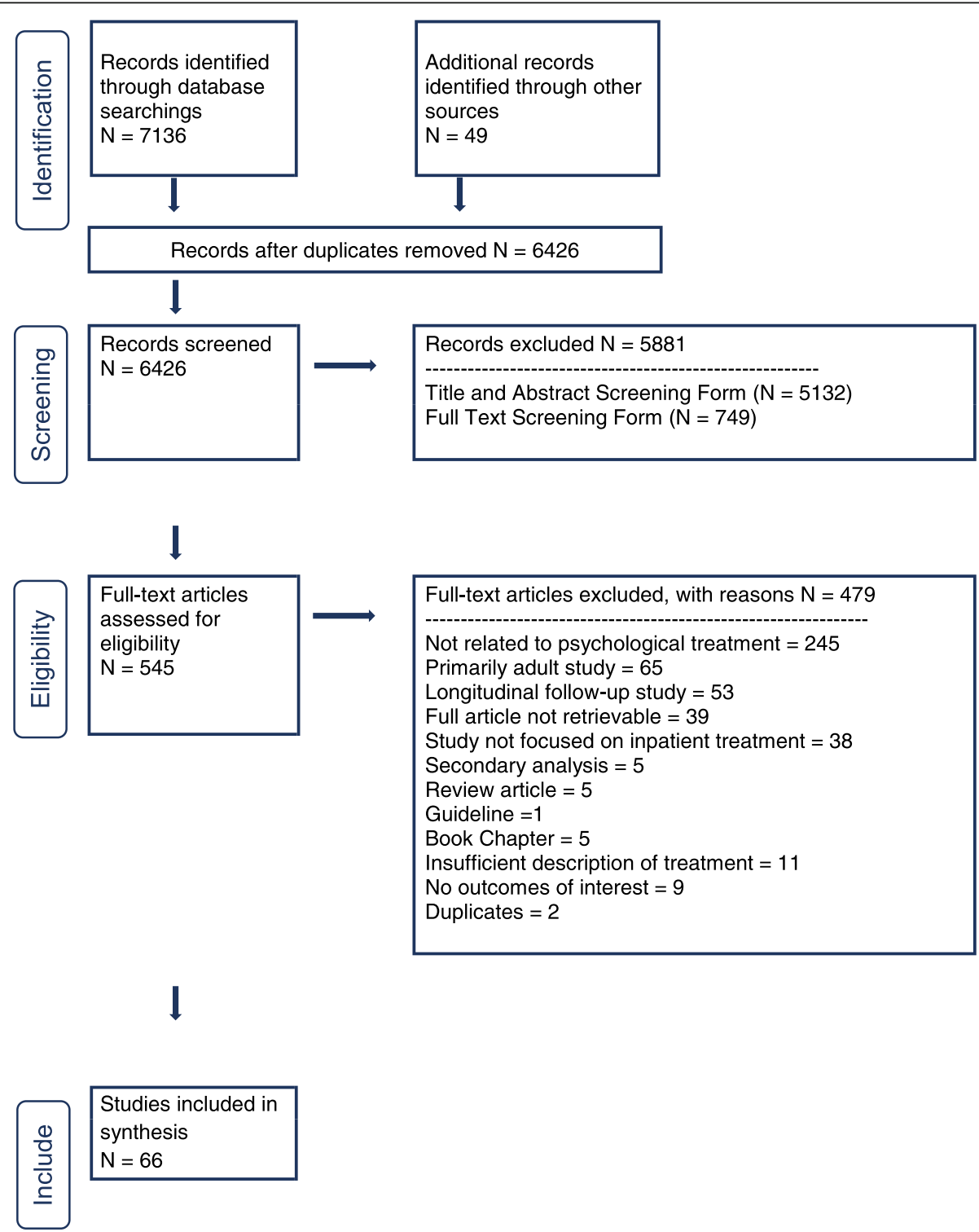

Fig. 1 PRISMA (Preferred Reporting Items for Systematic Reviews and Meta-Analyses) flow diagram of study selection 
presented below. The risk of bias as assessed by the GRADE system was deemed as high for all included studies.

\section{Inpatient ED programs for anorexia nervosa Primary outcome - weight gain}

We failed to identify any RCTs exploring outcomes of inpatient treatment specifically for pediatric AN, including atypical anorexia nervosa. We identified twenty studies (total $n=1091$ ) describing inpatient treatment based on an integrative approach for AN, including psychiatric, medical, nutritional, and pharmacologic management, as well as individual, group and family therapy along with skilled nursing support [18-37]. None of these studies included control or comparison groups. Various measures of change in weight were used across these studies. Mean change in weight was positive in all studies. Mean LOS ranged widely between studies (Table 1).

Three studies (total $n=39$ ) examined inpatient treatment utilizing a family-based approach [38-40], and three papers (total $n=296$ ) reported on inpatient treatment utilizing a cognitive behavioural (CBT) approach [41-43]. In all studies patients gained weight in hospital, although measures by which weight changes were reported varied, as did LOS (Table 1).

Fourteen additional studies reported on a behaviour therapy approach (total $n=218$ ) [44-57]. Various approaches to reporting change in weight were used, and all studies reported a positive change in weight from admission to discharge (Table 1). Of interest, Collins et al. (1983) reported that LOS was correlated to admission weight and feeding mode (i.e. oral vs nasogastric tube (NGT) feeds), and reported that the highest LOS was in those $<75 \%$ Treatment Goal Weight (TGW) at admission and requiring NGT feedings [49]. Another cohort study, by Solanto et al. (1994), reported weight gain under two types of behaviour contracts, varying only with regards to the expected rate of weight gain as measured every 4 days (q4d) (i.e. $0.36 \mathrm{~kg} / \mathrm{q} 4 \mathrm{~d}$ vs $0.55 \mathrm{~kg} / \mathrm{q} 4 \mathrm{~d}$ ) [56]. Those treated under the contract with higher weight targets gained weight at a faster rate and gained more weight overall.

Two reports (total $n=6$ ) were included in which patients were treated within an inpatient program using a psychodynamic approach $[58,59]$. The LOS and weekly weight gain for these patients varied substantially (Table 1).

Finally, two reports examined the effect on weight of admission to a general pediatrics unit with supportive psychotherapy $[37,60,61]$. In both studies patients gained weight (Table 1).

\section{Symptom change}

While all of the observational studies of patients with AN using an integrative framework for inpatient treatment reported on change in weight, fewer reported on change in ED symptoms or psychopathology (Table 1). Four studies reported on changes in the Eating Disorder Examination-Questionnaire (EDE-Q) [22, 24, 35, 36]. In only one of these studies, Fennig et al's (2015) [36], a significant pre-post difference $(n=51, p<0.05)$ was found and attributed predominantly to changes in restraint and eating concerns subscales. Of note, BMI at discharge was higher in the Fennig et al. (2015) study than the other three studies that reported on EDE-Q scores. Three studies (total $n=126$ ) reported change in Eating Attitude Test (EAT) scores at admission and discharge [21, 30, 32]. The difference in EAT scores was noted to improve in two of the studies [21, 32]. Fennig et al. (2015), compared scores on the Eating Disorder Inventory-2 (EDI-2) at admission and discharge and found no significant change in total or subscale scores [36].

Schlegl et al. (2016), used a CBT framework for treatment and reported on symptom change using EDI-2 scores [42]. All subscales showed significant improvements (Table 1).

Several studies using a behaviour therapy approach reported on symptom change during admission (Table 1). Cinciripini et al. (1983) described a case report in which purging after meals decreased from $48 \%$ of meals/week to $0 \%$ of meals per week [47]. Two other studies reported on EAT scores, both of which showed a reduction in scores during admission $[44,57]$. Of note, Alessi et al. (1989) reported that EAT scores remained high for the first 7 weeks of treatment (with weight gain of $4.5 \mathrm{~kg}$ over the first 7 weeks) and scores then dropped (from total score of 60 to 10) during the last 3 weeks of a 10week admission. Steinhausen et al. (1985) reported symptom change through EDI scores and noted that the mean "Drive for Thinness" scores decreased significantly over the course of admission $(p=0.02)$ [57].

\section{Measures of change in motivation}

Castro-Fornieles et al. (2007) measured motivation for change using the Anorexia Nervosa Stage of Change Questionnaire (ANSOCQ) at admission and discharge in an inpatient program utilizing an integrative framework [21]. Change in mean ANSOCQ score was noted to be statistically significant; however, both admission and discharge scores were characterized as within the "preparation" phase of motivation, and wide confidence intervals were reported (Table 1).

\section{Inpatient programs for mixed ED diagnoses Weight gain}

Three studies using an integrative approach (total $n=$ 239) were included and reported on weight gain during inpatient treatment for patients with mixed ED diagnoses $[9,28,30]$ (Table 2). The studies included in this 


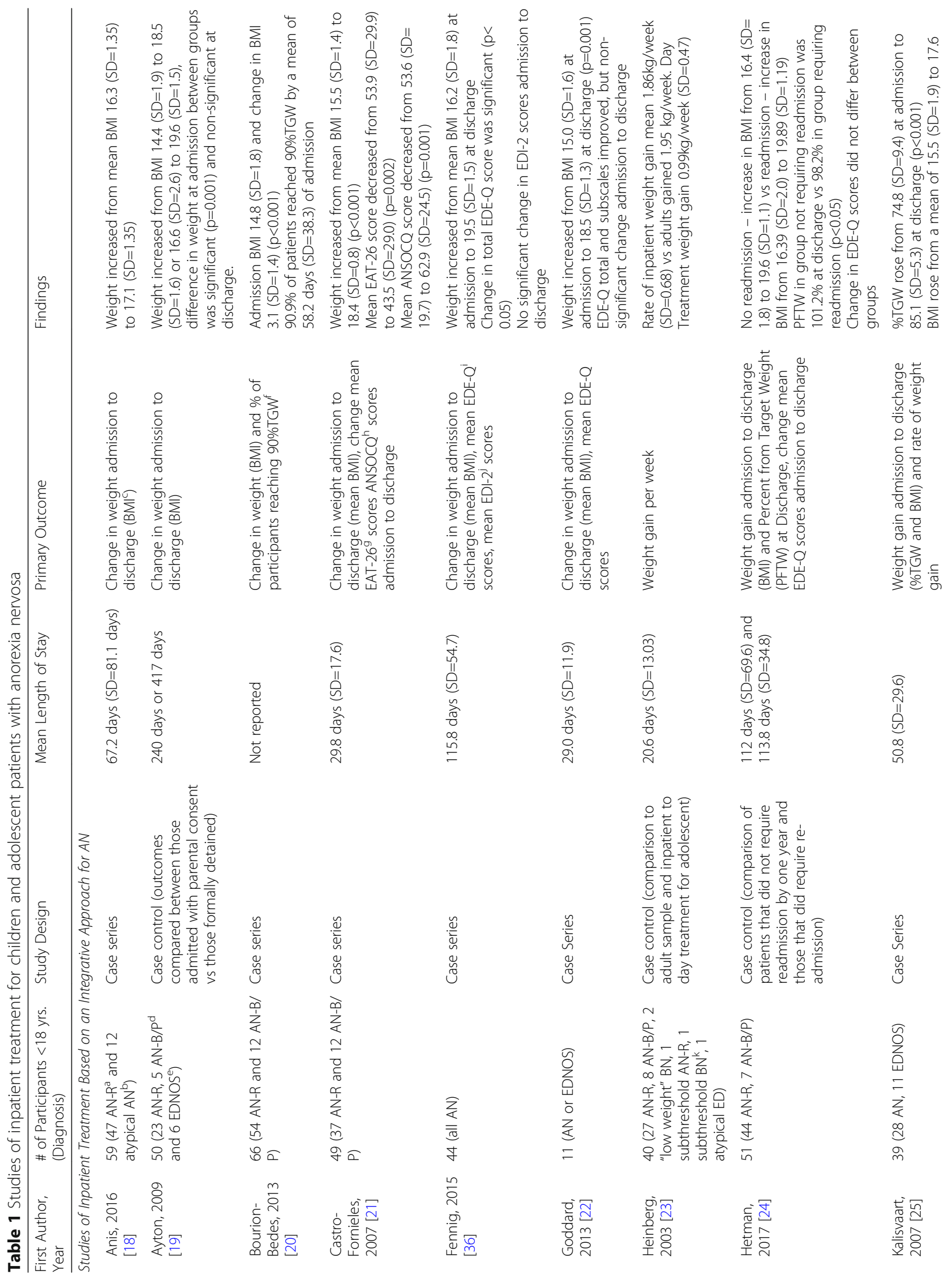




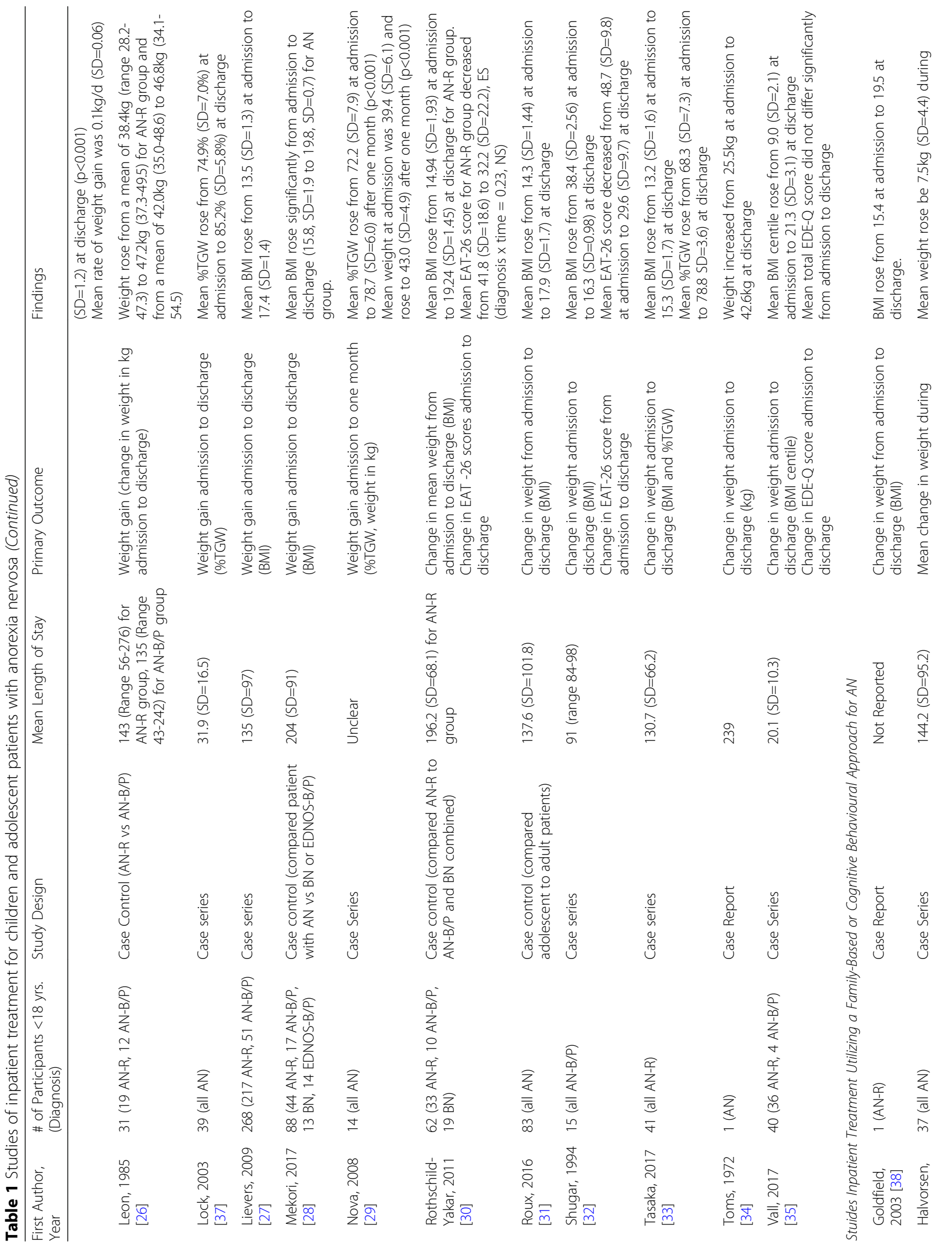




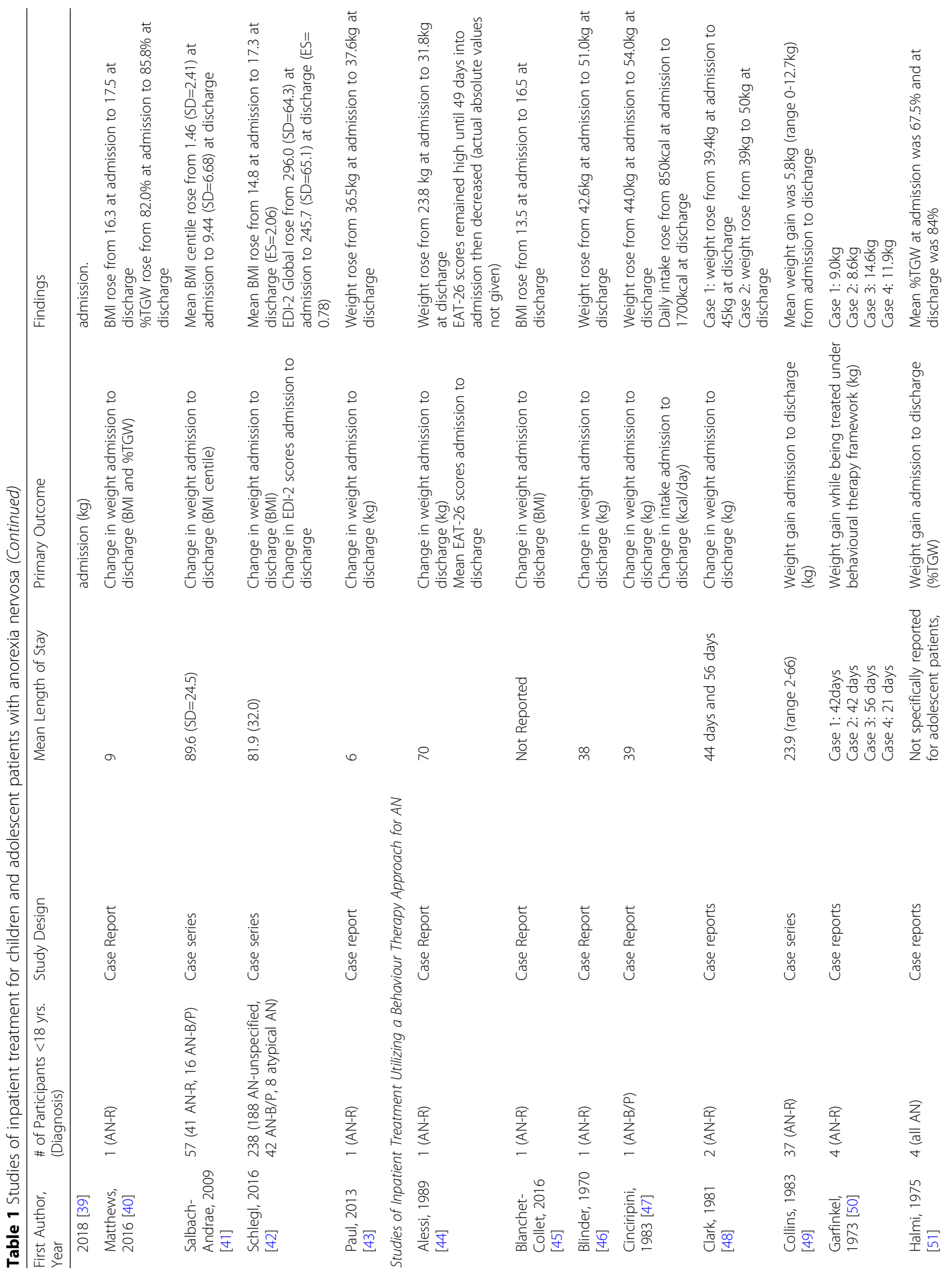




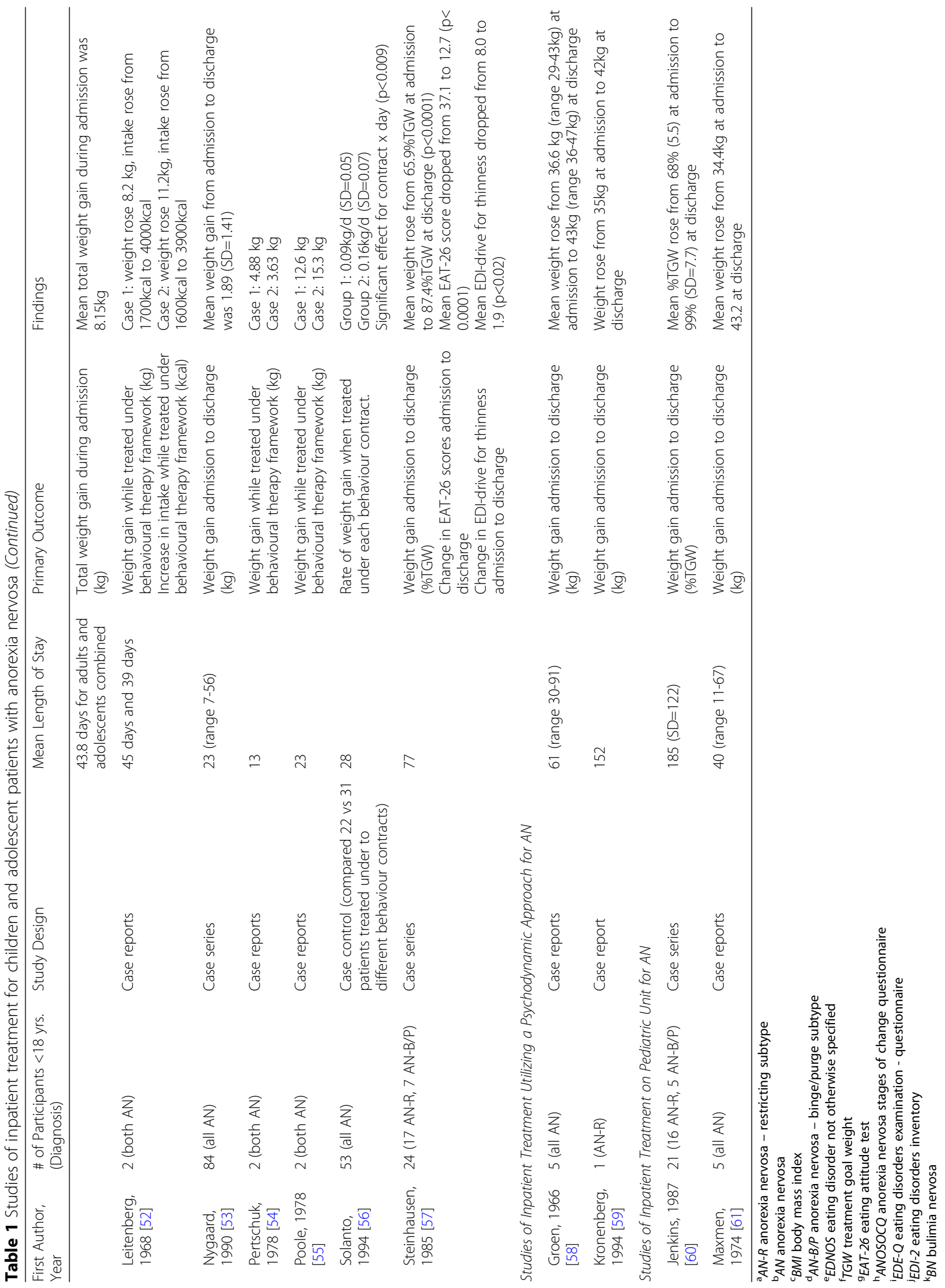


Table 2 Studies of inpatient treatment for children and adolescents mixed eating disorder diagnoses

\begin{tabular}{|c|c|c|c|c|c|}
\hline Author, Year & $\begin{array}{l}\text { \# of Participants } \\
\text { (Diagnosis) }\end{array}$ & Study Design & $\begin{array}{l}\text { Mean Length of } \\
\text { Stay }\end{array}$ & Primary Outcome & Finding \\
\hline Mekori, 2017 [28] & $\begin{array}{l}88 \text { (44 AN-R, } 17 \text { AN- } \\
\text { B/P, } 13 \text { BN, } 14 \\
\text { EDNOS-B/P) }\end{array}$ & $\begin{array}{l}\text { Case control } \\
\text { (compared patient } \\
\text { with AN vs BN or } \\
\text { EDNOS-B/P) }\end{array}$ & $204(S D=91)$ & $\begin{array}{l}\text { Weight gain admission } \\
\text { to discharge (BMI) }\end{array}$ & $\begin{array}{l}\text { Mean BMI rose significantly } \\
\text { from admission to discharge } \\
\left(15.8, \mathrm{SD}^{\mathrm{a}}=1.9 \text { to } 19.8, \mathrm{SD}=\right. \\
0.7) \text { and did not increase } \\
\text { significantly in the BN/EDNOS } \\
\text { group }(19.8, \mathrm{SD}=2.1 \text { to } 21.1 \text {, } \\
\mathrm{SD}=1.3) ; \mathrm{F} \text { (group } \times \text { time) }= \\
88.1, p<0.0001)\end{array}$ \\
\hline Morris, 2015 [9] & $\begin{array}{l}89 \text { (70 AN, } 2 \text { atypical } \\
\text { AN, } 1 \text { BN, } 16 \\
\text { Unspecified ED) }\end{array}$ & Case series & $141.1(\mathrm{SD}=125.7)$ & $\begin{array}{l}\text { Weight gain admission } \\
\text { to discharge (mean } \\
\text { weekly weight gain and } \\
\text { BMI) }\end{array}$ & $\begin{array}{l}\text { Mean weekly weight gain was } \\
0.43 \mathrm{~kg} / \text { week and there was a } \\
\text { significant rise in mean BMl } \\
\text { admission to discharge }(p< \\
0.001 \text { ) }\end{array}$ \\
\hline $\begin{array}{l}\text { Rothschild-Yakar, } \\
2011\end{array}$ & $\begin{array}{l}62(33 \mathrm{AN}-\mathrm{R}, 10 \mathrm{AN}- \\
\mathrm{B} / \mathrm{P}, 19 \mathrm{BN})\end{array}$ & $\begin{array}{l}\text { Case control } \\
\text { (compared AN-R } \\
\text { to AN-B/P and BN } \\
\text { combined) }\end{array}$ & $\begin{array}{l}196.2(S D=68.1) \\
\text { for } A N-R \text { group, } \\
178.8(S D=69) \text { for } \\
\text { AN-B/P and BN }\end{array}$ & $\begin{array}{l}\text { Change in mean weight } \\
\text { from admission to } \\
\text { discharge (BMI) } \\
\text { Change in EAT }-26 \\
\text { scores admission to } \\
\text { discharge }\end{array}$ & $\begin{array}{l}\text { Mean BMI rose from } 14.94 \\
(S D=1.93) \text { at admission to } \\
19.24(S D=1.45) \text { at discharge } \\
\text { for } A N-R \text { and from } 18.80(S D= \\
3.99) \text { to } 20.15(S D=2.29) \text { for } \\
\text { AN-B/P and BN. ES (diagnosis } x \\
\text { time }=0.59, p<0.001 \text { ) } \\
\text { Mean EAT-26 score decreased } \\
\text { for AN-R group from } 41.8 \\
(S D=18.6) \text { to } 32.2(S D=22.2) \\
\text { and in AN-B/P and BN group } \\
\text { from 46.7 (SD }=15.0) \text { to } 28.8 \\
(S D=14.7) . E S \text { (diagnosis } x \\
\text { time }=0.23, N S)\end{array}$ \\
\hline
\end{tabular}

section reported outcomes for various eating disorders (ie AN, BN, OSFED and EDNOS) as a combined group rather than differentiating outcomes by diagnosis. In all 3 studies patients gained weight from admission to discharge. Not surprisingly, in the 2 studies that differentiated anorexia nervosa-restricting subtype (AN-R) from other ED diagnoses, there was a significantly greater increase in Body Mass Index (BMI) for the group containing $\mathrm{AN}-\mathrm{R}$ patients $[28,30]$.

\section{Symptom change}

Rothschild-Yakar et al. (2013) compared symptom change from admission to discharge in an integrative inpatient treatment program for mixed ED diagnoses, using the EAT-26 in a group of patients with AN-R vs anorexia nervosa binge-purge subtype (AN-BP) or bulimia nervosa $(\mathrm{BN})$ [30]. Overall there was a statistically significant improvement in EAT-26 scores over the course of the admission $(p<0.001)$, and no significant difference in change in EAT-26 scores by diagnosis.

\section{Inpatient programs for bulimia nervosa}

We identified only one study that reported outcomes of inpatient treatment specifically for youth with $\mathrm{BN}$ [62]. The treatment provided was based on behaviour therapy and outcomes focused primarily on changes from admission to discharge in serotonin levels, as measured by 5 hydroxytriptamine induced calcium release from platelets.
As such, this study was limited in that the only reported ED-specific outcome was change in BMI, and weight decreased slightly over admission (Table 3).

\section{Inpatient programs for ARFID Weight}

Three case reports or case series were identified which described inpatient treatment of a total of eight children with ARFID treated using either a family-based or CBT or behavioural therapy approach [63-65]. Weight gain was reported in two studies (Table 4).

\section{Change in Oral intake}

Singer et al. (1992) reported on change in caloric intake in $\mathrm{kcal} /$ day for three patients with ARFID using a CBT inpatient treatment [64]. Oral intake rose for all three patients over the course of admission (Table 4).

Pitt and Middleman (2018) reported on two cases of adolescents with ARFID [65]. After admission, nasojejunal (NJ) tubes were placed to initiate refeeding when oral feeding was not tolerated. The authors reported that the use of an individualized behaviour plan for each patient providing reinforcements for eating was the critical factor which helped these patients to tolerate oral intake without vomiting and allowed for the removal of the NJ tubes (Table 4). 
Table 3 Studies of inpatient treatment for children and adolescent with bulimia nervosa

\begin{tabular}{lcccll}
\hline Author, Year & $\begin{array}{l}\text { \# of Participants } \\
\text { (Diagnosis) }\end{array}$ & Study Design & Mean Length of Stay & Primary Outcome & Finding \\
\hline Wockel, 2009 [62] & 13 (all BN) & Case series & $69(\mathrm{SD}=24.5)$ & $\begin{array}{l}\text { Weight change admission } \\
\text { to discharge (BMI) }\end{array}$ & $\begin{array}{l}\text { Mean BMl decreased by 0.3 kg } \\
\text { (SD=1.4) from admission to } \\
\text { discharge }\end{array}$ \\
\hline
\end{tabular}

\section{Combined inpatient and day treatment programs Weight gain}

Five studies summarized the experience of 264 adolescents with AN treated as inpatients followed immediately by day treatment (DTP), utilizing either an integrative or CBT approach [66-70]. Studies considered as providing combined inpatient and day treatment programs reported on change from the point of admission to an inpatient program through the end of their involvement in day treatment. In these studies, all patients received inpatient treatment directly followed by day treatment services. All five studies included inpatient treatment for medically unstable patients followed by transfer to a DTP once medical stability was attained (Table 5). Total mean LOS (i.e. inpatient and DTP combined) varied substantially between studies. Weight increased in all studies (Table 5).

\section{Symptom change}

Symptom change was reported using various scales in two studies of combined inpatient and DTP $[66,68]$. Hillen et al. (2015) failed to demonstrate a significant change in EDI-2 scores. Dalle Grave et al. (2014) reported a significant decrease in EDE-Q scores pre to post treatment for global score and for all subscales other than Shape Concern. The percentage of patients with Global EDE-Q scores $<1$ SD above the community mean at admission was $2 \%(+/-7.7)$ and at discharge it was $10 \%(+/-38.5)$, suggesting a decrease in ED thoughts and urges with treatment (Table 5).

\section{Motivation}

Hillen et al. (2015) reported on change in motivation as measured by the ANSOCQ in 35 patients [68]. Overall mean scores increased by 21.7 points which signified moving from contemplation to preparation phases. Overall, 29.4\% (up from $0 \%$ at admission) of patients were classified as being in "maintenance phase" and $26.5 \%$ (up from 15\% at admission) in "action phase" at time of discharge from DTP (Table 5).

\section{Overall outcome}

Treat et al. (2008) included 71 patients who combined inpatient and DTP and reported on "overall outcome" [70]. At the end of DTP $35.2 \%$ were deemed to have an excellent outcome, $26.8 \%$ were deemed to have good outcome, $14.1 \%$ were deemed below average outcome and $23.9 \%$ were described as having a poor outcome, according to definitions assigned by the authors which

Table 4 Studies of inpatient treatment for children and adolescents with avoidant restrictive food intake disorder

\begin{tabular}{|c|c|c|c|c|c|}
\hline Author, Year & $\begin{array}{l}\text { \# of Participants } \\
\text { (Diagnosis) }\end{array}$ & Study Design & $\begin{array}{l}\text { Mean Length } \\
\text { of Stay }\end{array}$ & Primary Outcome & Findings \\
\hline Spettigue, 2018 [63] & $\begin{array}{l}3 \text { (2 ARFID }{ }^{a} \text {-aversive } \\
\text { subtype, } 1 \text { ARFID- } \\
\text { mixed subtype) }\end{array}$ & Case reports & 53 days & $\begin{array}{l}\text { Change in weight } \\
\text { gain (\%TGW) }\end{array}$ & $\begin{array}{l}\text { Case 1: Weight increased from } \\
83 \% \text { TGW to } 100 \% \text { TGW. } \\
\text { Case 2: Weight increased from } \\
75.8 \% \text { TGW to } 100 \% \text { TGW. } \\
\text { Case 3: Weight increased from } \\
72 \% \text { TGW to } 88 \% \text { TGW }\end{array}$ \\
\hline Singer, 1992 [64] & $\begin{array}{l}3 \text { (1 ARFID - aversive } \\
\text { subtype, } 2 \text { ARFID- } \\
\text { mixed subtype) }\end{array}$ & Case reports & $\begin{array}{l}32 \text { days (range } \\
16-60 \text { days) }\end{array}$ & $\begin{array}{l}\text { Change in weight } \\
(\mathrm{kg}) \\
\text { Increase in caloric } \\
\text { intake from } \\
\text { admission to } \\
\text { discharge (kcal/day) }\end{array}$ & $\begin{array}{l}\text { Case 1: Increase in weight } \\
\text { from } 21.8 \mathrm{~kg} \text { to } 24.5 \mathrm{~kg} \text { (over } \\
60 \text { days), intake increased from } \\
1557 \mathrm{kcal} / \mathrm{d} \text { to } 2208 \mathrm{kcal} / \mathrm{d} \text { ) } \\
\text { Case } 2: \text { Increase in weight } \\
\text { from } 21.4 \mathrm{~kg} \text { to } 22.6 \mathrm{~kg} \text { (over } \\
16 \text { days), intake increased from } \\
740 \mathrm{kcal} / \mathrm{d} \text { to } 1500 \mathrm{kcal} / \mathrm{d} \text { ) } \\
\text { Case } 3: \text { Increase in weight } \\
\text { from } 17.7 \mathrm{~kg} \text { to } 18.0 \mathrm{~kg} \text { (over } \\
19 \text { days), intake increased from } \\
1200 \mathrm{kcal} / \mathrm{d} \text { to } 1500 \mathrm{kcal} / \mathrm{d}\end{array}$ \\
\hline Pitt, 2018 [65] & $\begin{array}{l}2 \text { (ARFID - mixed } \\
\text { subtype) }\end{array}$ & Case reports & Not reported & $\begin{array}{l}\text { Reduction in } \\
\text { vomiting and } \\
\text { tolerance of oral } \\
\text { intake without } \\
\text { emesis }\end{array}$ & $\begin{array}{l}\text { Vomiting frequency reduced } \\
\text { and oral tolerance improved } \\
\text { although specifics not } \\
\text { reported }\end{array}$ \\
\hline
\end{tabular}




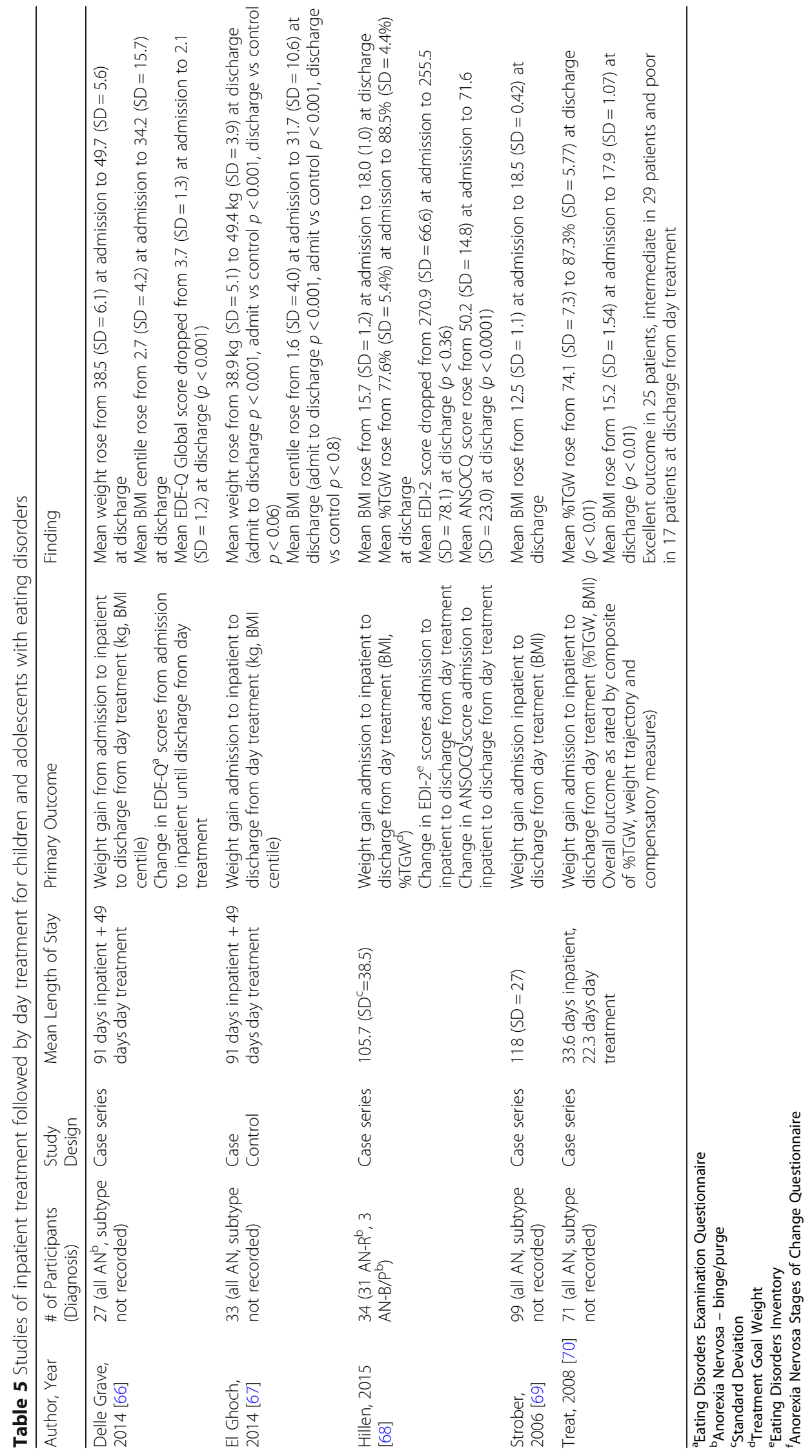


included a combination of \% ideal BMI, maintenance of weight and compensatory behaviours (Table 5).

\section{Adjunctive treatments \\ Adjunctive cognitive remediation therapy (CRT)}

Four studies reported on the addition of CRT to integrative inpatient treatment for patients with AN (total $n=$ 127) [71-74] (Table 6). Herbrich et al. (2017) described no difference in the change in weight between adolescent patients who received 10 sessions of CRT over 10 weeks compared to those who received treatment as usual (TAU) in a quasi-experimental design $(n=24$ in each group) [74]. The other three studies did not include a control group. Patients (total $n=79$ ) gained weight, but it was not possible to determine whether CRT had an impact on weight gain above and beyond what would have been expected by inpatient treatment [71-73].

Three studies of CRT added to inpatient treatment for AN reported on symptom change (Table 6). A report of two cases by Asch et al. (2014) described that total scores on the EAT decreased for one patient and increased in the other patient and Eating Behavior Rating Scale (EBRS) scores decreased slightly for both patients, by the end of 10 weeks [71]. Another study by Harrison et al. (2018), included 70 hospitalized patients who received individual CRT, and noted no change in EDE-Q scores [73].

In a study by Harrison et al. (2018), patients reported on change in motivation as measured by the MSCARED before and after the course of CRT [73]. There was a statistically significant shift in motivation noted $(p<$ 0.001 ), with $42.9 \%$ in preparation, action or maintenance stages of change at initiation of CRT, and with $95.7 \%$ in one of those stages of change after receiving CRT (Table 6). Due to the design of this study it was not possible to differentiate the effect of inpatient treatment alone from inpatient treatment plus CRT.

\section{Adjunctive multi-family/parent group therapy}

A study by Depestele et al. (2017) reported on 112 patients with various ED diagnoses admitted to an inpatient ED unit providing an integrative therapy approach to treatment, who also received either adjunctive multi-family group therapy (MFT, $n=62$ ) or adjunctive multi-parent group therapy (MPT, $n=50$ ) [75]. Both MPT and MFT interventions "promoted an autonomysupportive parental attitude and the adolescents' autonomy and self-determination." Results reported a main effect of time on drive for thinness $(p<0.001)$ and body dissatisfaction $(p<0.001)$ as measured by EDI-2. Both scales improved independent of the type of intervention (Table 6).

\section{Adjunctive bright light therapy}

A study by Janas-Kozik et al. (2011) examined patients with AN and depressive symptoms ( $>17$ on Hamilton Depression Rating Scale) who were admitted to a CBTbased inpatient program and treated adjunctively with Bright Light Therapy [76]. In this study patients were randomized to receive either daily 30 min of Bright Light Therapy $(\mathrm{BLT})+$ inpatient treatment $(n=12) \times 6$ weeks, or inpatient treatment only $\times 6$ weeks $(n=12)$. Patients in both groups had a significant change in their BMI during the 6-week study; however, weight change from baseline was statistically significant by week $3(p=0.038)$ in the BLT group but only at week $6(p=0.048)$ in the TAU group (Table 6).

\section{Adjunctive meal support}

Three studies examined the effect of meal support/ supervision as part of inpatient treatment for groups of patients with mixed ED diagnoses [77-79] (Table 6). In the two studies examining weight gain, there were no significant differences between cohorts who received meal support (total $n=77$ ) and those who did not (total $n=78$ ) on the rate of weight gain per day, although there was a trend towards greater weight gain per day in the group who received meal support $[78,79]$. In these two studies, the approach to meals for patients who did not receive meal support was not documented. A separate study by Couturier \& Mahmood (2009) reported a significant decrease in the rate of nasogastric tube feeds in the cohort of patients treated on an inpatient unit after the institution of consistent meal support [77].

\section{Selective versus non-selective menus}

Leacy \& Cane (2012) $(n=22)$ compared the rate of weight gain and EDE-Q scores in patients with AN who received non-selective menus (i.e. meals chosen by a dietician) or selective menus (i.e. meals chosen by the patient, under the direction of a dietician) as part of their inpatient treatment [80]. The non-selective menu group gained weight significantly faster than those in the selective menu group $(p=0.02)$ (Table 6). No significant differences were found on any of the EDE-Q items related to eating concern. Overall change in EDE eating concern scores in this study were low, ranging from 0.6 to 1.1 (Table 6).

\section{Conclusions}

The aim of the present review was to identify the scope and benefits of psychological treatment provided to children and adolescents with EDs in inpatient settings. We identified 66 studies that demonstrated considerable heterogeneity in the types of treatment provided and the outcomes reported. While all studies focused on inpatient treatment, in some studies this treatment was 


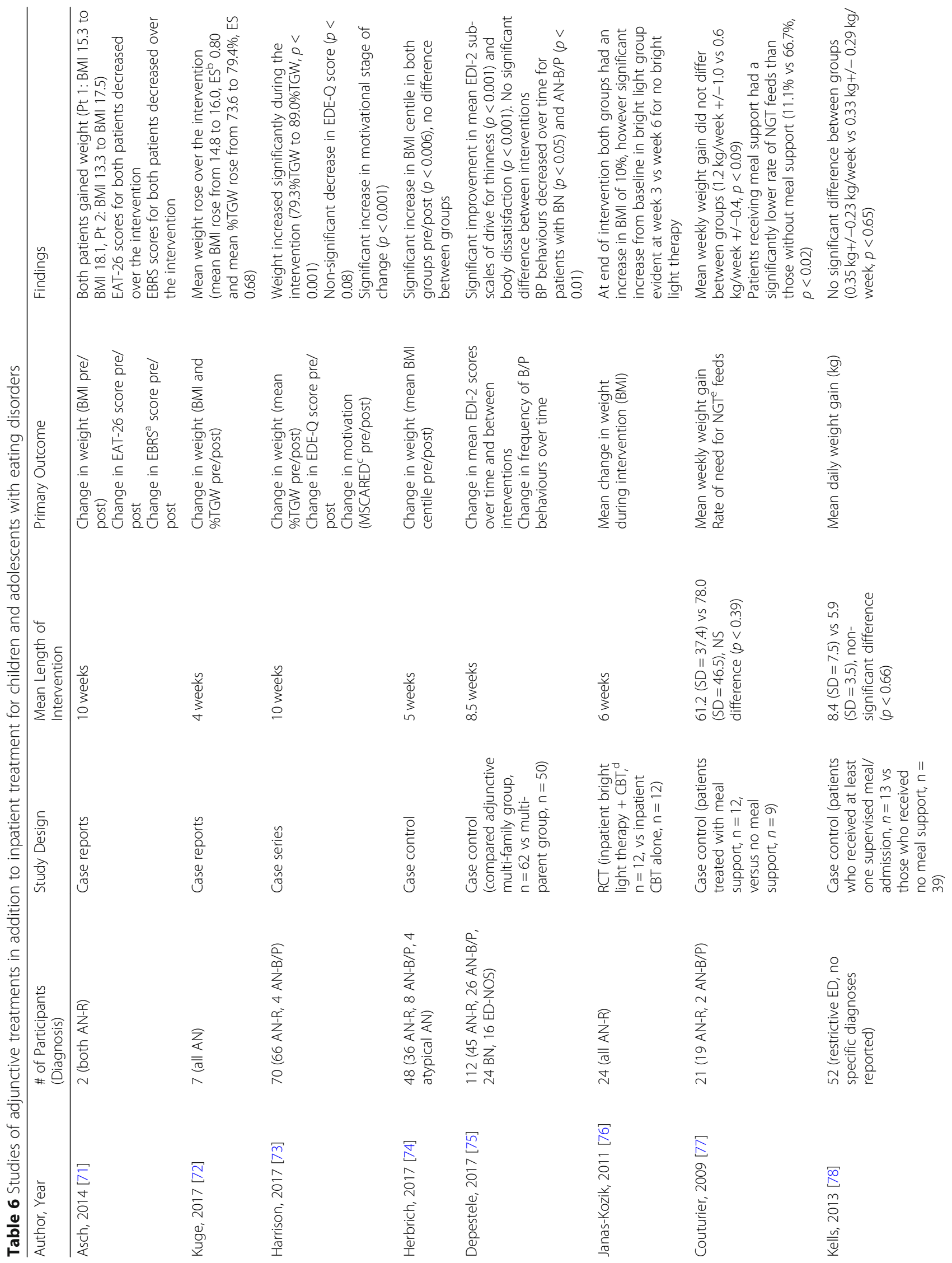




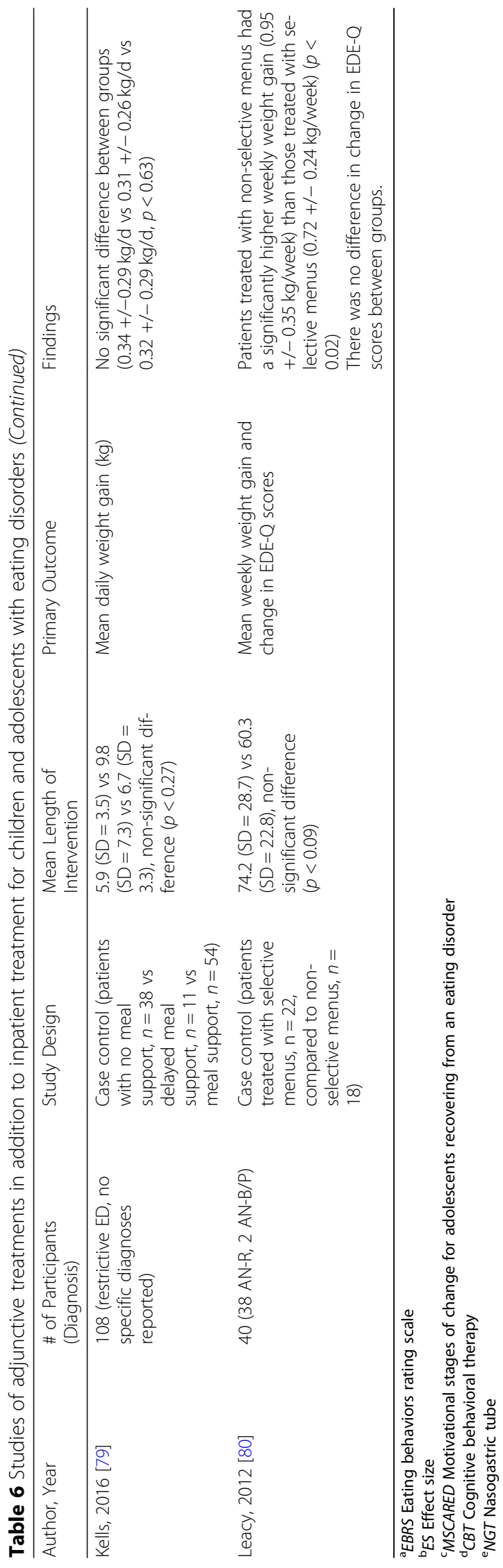


provided on a pediatric unit and in other studies it was provided on a psychiatric unit, either designed specifically for the treatment of patients with EDs or not. The treatment provided also varied with regards to the therapeutic modalities utilized, length of stay in intensive treatment, and the goals or expectations of treatment.

Despite the presence of substantial biases, and lack of control groups, each of the specialized ED inpatient programs and non-specialized general pediatric wards reported success in helping underweight patients with restrictive eating disorders gain weight. Beyond this finding, given the overwhelming heterogeneity of methods described, there is little that can be concluded from the various studies contained within.

Similarly, it is impossible to draw any conclusions as to which adjunctive treatments might be most helpful when treating youth with AN in hospital. While adjunctive treatments were examined, i.e. the use of meal support, selective versus non-selective menus, bright light therapy, CRT, and multi-family versus multi-parent group, the quality of the studies does not allow us to draw any conclusions about the effectiveness of these treatments. There are also some interesting omissions from this literature on adjunctive inpatient treatments, including no papers looking at outcomes of adjunctive yoga, exercise programs, art therapy, journaling, mindfulness, dialectical behaviour skills groups, or individual or group motivational enhancement therapy. Furthermore, there are insufficient studies of inpatient treatment for EDs other than AN, such that no conclusions can be drawn about the effectiveness of inpatient programs for the treatment of BN, ARFID or BED.

Finally, none of these studies serve to identify the specific factors most associated with a successful inpatient program for the treatment of children and adolescents with EDs. Clinical experience often points to a number of factors that appear to have clinical relevance, including a specialized, experienced multidisciplinary treatment team that combines confidence, compassion, consistency and the ability to create a safe environment where it is assumed that patients will take the nutrition they need to recover. These units typically provide skilled meal support and attend to patients' medical, nutritional and psychological needs, with a focus on weight gain, renourishment and symptom interruption. It is widely recognized that families need to be supported and educated, and patients benefit from therapy which helps them to separate from and externalize the illness, thereby improving their motivation for recovery. Unfortunately, few of these factors have been identified, studied or discussed in the literature, there are no RCTs to provide guidance, and it is impossible to compare one inpatient program to another based on studies to date. It is also impossible to discern the optimal LOS, which combination of individual, group or family therapy is essential, or to determine the ideal group therapy content.

Limitations of this review include the inability to complete a meta-analysis or quantitative analysis due to the low quality and high heterogeneity of the studies available, the lack of inclusion of the search term "unspecified feeding and eating disorder" which could have yielded additional studies on this topic, a lack of studies specifically reporting on particular diagnoses including EDNOS, OSFED or atypical anorexia nervosa, and an inability to disaggregate findings based on subgroup such as gender or age (ie children vs adolescents).

Future research should focus on resolving these deficiencies through the use of studies based on high quality research methods, standardized operation of reporting treatment variables and outcomes, and multi-site designs to gather data on larger numbers of participants. Given the paucity of research in this field, the prolonged LOS (and associated costs) often observed, as well as the substantial variability by which treatments are delivered, it is critical that basic indicators of admission and treatment are standardized and reported, in order to continue to move the field forward. Only with improved research methods and reporting will it be possible to identify the key components of successful inpatient treatment and to improve outcomes for children and adolescents with EDs.

\section{Supplementary information}

Supplementary information accompanies this paper at https://doi.org/10. 1186/s40337-020-00307-2.

Additional file 1. Database Search Strategies.

\section{Abbreviations}

AN: Anorexia nervosa; AN-R: Anorexia nervosa - restricting subtype; AN-B/ $\mathrm{P}$ : Anorexia nervosa - binge/purge subtype; ANSOCQ: Anorexia nervosa stages of change questionnaire; ARFID: Avoidant restrictive food intake disorder; BED: Binge eating disorder; BLT: Bright light therapy; BMI: Body mass index; BN: Bulimia nervosa; CBT: Cognitive behaviour therapy; CRT: Cognitive remediation therapy; DTP: Day treatment program; EAT26: Eating attitude test; ED: Eating disorder; EDE-Q: Eating disorder examination - questionnaire; EDI-2: Eating disorder inventory; EDNOS: Eating disorder not otherwise specified; GRADE: Grading of Recommendations, Assessment, Development and Evaluations; MPT: Multi-parent group therapy; MFT: Multi-family group therapy; NGT: Nasogastric tube; NJ: Nasojejunal; OSFED: Other specified feeding and eating disorder; PRISMA: Preferred Reporting Items for Systematic Reviews and Meta-analyses; RCT: Randomized control trial; TAU: Treatment as usual

\section{Acknowledgements}

The authors would like to acknowledge the contribution of Neera Bhatnagar (library scientist) who supported the initial abstract search, as well as Cheryl Webb and Dr. Natasha Snelgrove who contributed to this work through screening of abstracts.

Authors' contributions

All authors contributed to the screening of articles for inclusion/exclusion. LI and JC assessed the risk of bias for the articles included. The authors contributed to and approved the final manuscript. 


\section{Funding}

This study did not receive any funding.

\section{Availability of data and materials}

Data sharing is not applicable to this article as no datasets were generated or analysed during the current study.

\section{Ethics approval and consent to participate}

Not applicable.

\section{Consent for publication}

Not applicable.

\section{Competing interests}

The authors declare that they have no competing interests.

\section{Author details}

'Department of Psychiatry, Children's Hospital of Eastern Ontario, University of Ottawa, Ottawa, ON K1H 8L1, Canada. ${ }^{2}$ Children's Hospital of Eastern Ontario Research Institute, Ottawa, ON K1H 8L1, Canada. ${ }^{3}$ Division of Adolescent Health, Department of Pediatrics, Children's Hospital of Eastern Ontario, University of Ottawa, Ottawa, ON K1H 8L1, Canada. ${ }^{4}$ Department of Psychiatry \& Behavioural Neurosciences, McMaster University, Hamilton, ON L8N3Z5, Canada.

\section{Received: 7 January 2020 Accepted: 28 May 2020}

\section{Published online: 03 July 2020}

\section{References}

1. Le Grange D, Lock J, editors. Childhood and adolescence: looking at eating disorders when they start. New York: Guildford Press; 2011.

2. Hay P, Chinn D, Forbes D, Madden S, Newton R, Sugenor L, et al. Royal Australian and new Zealand College of Psychiatrists clinical practice guidelines for the treatment of eating disorders. Aust N Z J Psychiatry. 2014; 48(11):977-1008.

3. Lock J, La Via MC. American Academy of C, adolescent psychiatry committee on quality I. practice parameter for the assessment and treatment of children and adolescents with eating disorders. J Am Acad Child Adolesc Psychiatry. 2015;54(5):412-25.

4. Wilson GT, Shafran R. Eating disorders guidelines from NICE. Lancet. 2005; 365(9453):79-81.

5. Jauregui-Garrido B, Jauregui-Lobera I. Sudden death in eating disorders. Vasc Health Risk Manag. 2012:8:91-8.

6. Kastner D, Lowe B, Weigel A, Osen B, Voderholzer U, Gumz A. Factors influencing the length of hospital stay of patients with anorexia nervosa results of a prospective multi-center study. BMC Health Serv Res. 2018;18(1):22.

7. Nozoe SSY, Yoshioka M, Naruo T, Masuda A, Nagai N, Tanaka H. Clinical features of patients with anorexia nervosa: assessment of factors influencing the duration of in-patient treatment. J Psychosom Res. 1995;39(3):271-81.

8. Warnke I, Rossler W. Length of stay by ICD-based diagnostic groups as basis for the remuneration of psychiatric inpatient care in Switzerland? Swiss Med Wkly. 2008;138(35-36):520-7.

9. Morris J, Simpson AV, Voy SJ. Length of stay of inpatients with eating disorders. Clin Psychol Psychother. 2015;22(1):45-53.

10. Toulany A, Wong M, Katzman DK, Akseer N, Steinegger C, Hancock-Howard RL, et al. Cost analysis of inpatient treatment of anorexia nervosa in adolescents: hospital and caregiver perspectives. CMAJ Open. 2015;3(2):E192-7.

11. AM C, M G-P, JV S, F C, I B, A. F. Eating disorders-related hospitalizations in Portugal: a nationwide study from 2000 to 2014. Int J Eat Disord. 2017; 51(10):1201-6.

12. Stuhldreher N, Wild B, Konig HH, Konnopka A, Zipfel S, Herzog W. Determinants of direct and indirect costs in anorexia nervosa. Int J Eat Disord. 2015:48(1):139-46.

13. Gowers SG, Clark AF, Roberts C, Byford S, Barrett B, Griffiths A, et al. A randomised controlled multicentre trial of treatments for adloescent anorexia nervosa including assessment of cost-effectiveness and patient acceptability - the TOuCAN trial. Health Technol Assess. 2010;14(15):1.

14. Herpertz-Dahlmann B, Schwarte R, Krei M, Egberts K, Warnke A, Wewetzer C, et al. Day-patient treatment after short inpatient care versus continued inpatient treatment in adolescents with anorexia nervosa (ANDI): a multicentre, randomised, open-label, non-inferiority trial. Lancet. 2014 383(9924):1222-9.

15. Madden S, Miskovic-Wheatley J, Wallis A, Kohn M, Lock J, Le Grange D, et al. A randomized controlled trial of in-patient treatment for anorexia nervosa in medically unstable adolescents. Psychol Med. 2015;45(2):415-27.

16. Moher D, Liberati A, Tetzlaff J, Altman DG, Group P. Preferred reporting items for systematic reviews and meta-analyses: the PRISMA statement. J Clin Epidemiol. 2009;62(10):1006-12.

17. Guyatt GH, Oxman AD, Vist G, Kunz R, Brozek J, Alonso-Coello P, et al. GRADE guidelines: 4. Rating the quality of evidence--study limitations (risk of bias). J Clin Epidemiol. 2011;64(4):407-15

18. Anis N, Isomaa R, Kaltiala-Heino R. Adolescent psychiatric inpatients with first hospitalization due to anorexia nervosa: can rehospitalization be predcited by clinical features. Psychiatr Fenn. 2016:47:76-94.

19. Ayton A, Keen C, Lask B. Pros and cons of using the mental health act for severe eating disorders in adolescents. Eur Eat Disord Rev. 2009; 17(1):14-23.

20. Bourion-Bedes S, Baumann C, Kermarrec S, Ligier F, Feillet F, Bonnemains C, et al. Prognostic value of early therapeutic alliance in weight recovery: a prospective cohort of 108 adolescents with anorexia nervosa. J Adolesc Health. 2013:52(3):344-50.

21. Castro-Fornieles J, Casula V, Saura B, Martinez E, Lazaro L, Vila M, et al. Predictors of weight maintenance after hospital discharge in adolescent anorexia nervosa. Int J Eat Disord. 2007;40(2):129-35.

22. Goddard E, Hibbs R, Raenker S, et al. A multi-centre cohort study of short term outcomes of hospital treatment for anorexia nervosa in the UK. BMC Psychiatry. 2013;13:287:1-14. https://doi.org/10.1186/1471-244X-13-287.

23. Heinberg $\sqcup$, Haug NA, Freeman YL, Ambrose D, Guarda AS. Clinical course and short-term outcome of hospitalized adolescents with eating disorders: the success of combining adolescents and adults on an eating disorders unit. Eat Weight Disord. 2003:8(4):326-31.

24. Hetman I, Brunstein Klomek A, Goldzweig G, Hadas A, Horwitz M, Fennig S. Percentage from target weight (PFTW) predicts re-hospitalization in adolescent anorexia nervosa. Isr J Psychiatry Relat Sci. 2017:54(3):28-34.

25. Kalisvaart $J \mathrm{~L}$, Hergenroeder AC. Hospitalization of patients with eating disorders on adolescent medical units is threatened by current reimbursement systems. Int J Adolesc Med Health. 2007;19(2):155-65.

26. Leon GR, Lucas AR, Colligan RC, Ferdinande RJ, Kamp J. Sexual, body-image, and personality attitudes in anorexia nervosa. J Abnorm Child Psychol. 1985; 13(2):245-57.

27. Strik Lievers L, Curt F, Wallier J, Perdereau F, Rein Z, Jeammet $P$, et al. Predictive factors of length of inpatient treatment in anorexia nervosa. Eur Child Adolesc Psychiatry. 2009;18(2):75-84.

28. Mekori E, Halevy L, Ziv SI, Moreno A, Enoch-Levy A, Weizman A, et al. Predictors of short-term outcome variables in hospitalised female adolescents with eating disorders. Int J Psychiatry Clin Pract. 2017;21(1):41-9.

29. Nova E, Lopez-Vidriero I, Varela P, Casas J, Marcos A. Evolution of serum biochemical indicators in anorexia nervosa patients: a 1-year follow-up study. J Hum Nutr Diet. 2007;21:23-30.

30. Rothschild-Yakar L, Lacoua L, Stein D. Changes in patient measures as predictors of therapists' ratings of treatment collaboration and change in eating disorder subgroups. Assessment. 2013;20(6):752-63.

31. Roux H, Ali A, Lambert S, Radon L, Huas C, Curt F, et al. Predictive factors of dropout from inpatient treatment for anorexia nervosa. BMC Psychiatry. 2016;16(1):339.

32. Shugar G, Krueger S. Aggressive family communication, weight gain, and improved eating attitudes during systemic family therapy for anorexia nervosa. Int J Eat Disord. 1995:17(1):23-31.

33. Tasaka K, Matsubara K, Takamiya S, Ishikawa SI, Iwata A, Nigami H. Longterm follow up of hospitalized pediatric anorexia nervosa restricting type. Pediatr Int. 2017;59(4):482-9.

34. Toms DA, Crisp AH. Weight phobia in an adolescent male with stunted development. J Psychosom Res. 1972;16(4):289-95.

35. Vall E, Wade TD. Predictors and moderators of outcomes and readmission for adolescent inpatients with anorexia nervosa: a pilot study. Clin PsycholUk. 2017:21(2):143-52

36. Fennig S, Brunstein Klomek A, Shahar B, Sarel-Michnik Z, Hadas A. Inpatient treatment has no impact on the core thoughts and perceptions in adolescents with anorexia nervosa. Early Interv Psychiatry. 2015;11(3):200-7.

37. Lock J, Litt I. What predicts maintenance of weight for adolescents medically hospitalized for anorexia nervosa? Eat Disord. 2003;11(1):1-7. 
38. Goldfield GS, Boachie A. Delivery of family therapy in the treatment of anorexia nervosa using telehealth. Telemed J E-Health. 2003;9(1):111-4.

39. Halvorsen I, Reas DL, Nilsen JV, Ro O. Naturalistic outcome of family-based inpatient treatment for adolescents with anorexia nervosa. Eur Eat Disord Rev. 2018;26(2):141-5.

40. Matthews A, Peterson CM. Intensive family-based therapy during an acute medical admission for anorexia nervosa: a case report. Clin Case Stud. 2016; 15(4):313-25.

41. Salbach-Andrae H, Schneider N, Seifert K, Pfeiffer E, Lenz K, Lehmkuhl U, et al. Short-term outcome of anorexia nervosa in adolescents after inpatient treatment: a prospective study. Eur Child Adolesc Psychiatry. 2009;18(11): $701-4$.

42. Schlegl S, Diedrich A, Neumayr C, Fumi M, Naab S, Voderholzer U. Inpatient treatment for adolescents with anorexia nervosa: clinical significance and predictors of treatment outcome. Eur Eat Disord Rev. 2016;24(3):214-22.

43. Paul P, Mehta S, Coffey BJ. Anorexia nervosa in a 14-year-old secondgeneration Hispanic adolescent boy. J Child Adolesc Psychopharmacol. 2013;23(4):295-9.

44. Alessi NE, Krahn D, Brehm D, Wittekindt J. Prepubertal anorexia nervosa and major depressive disorder. J Am Acad Child Adolesc Psychiatry. 1989;28(3): 380-4.

45. Blanchet-Collet C, Sider A, Gal B, Hanachi-Guidoum M, Melchior JC, Bouscary $D$, et al. Anorexia nervosa hyperactivity-induced ischemic colitis (ANHIC): a new cause of anaemia. Eat Weight Disord-St. 2016;21(3):507-10.

46. Blinder BJ, Freeman DM, Stunkard AJ. Behavior therapy of anorexia nervosa: effectiveness of activity as a reinforcer of weight gain. Am J Psychiatry. 1970;126(8):1093-8.

47. Cinciripini PM, Kornblith SJ, Turner SM, Hersen M. A behavioral program for the management of anorexia and bulimia. J Nerv Ment Dis. 1983;171(3): 186-9.

48. Clark DB, Munford PR. Behavioral consultation to pediatrics. Child Behavior Therapy. 1981;2(3):25-33.

49. Collins M, Hodas GR, Liebman R. Interdisciplinary model for the inpatient treatment of adolescents with anorexia nervosa. J Adolesc Health Care. 1983;4(1):3-8.

50. Garfinkel PE, Kline SA, Stancer HC. Treatment of anorexia nervosa using operant conditioning techniques. J Nerv Ment Dis. 1973;157(6):428-33.

51. Halmi KA, Powers $P$, Cunningham $S$. Treatment of anorexia nervosa with behavior modification. Effectiveness of formula feeding and isolation. Arch Gen Psychiatry. 1975;32(1):93-6.

52. Leitenberg H, Agras WS, Thomson LE. A sequential analysis of the effect of selective positive reinforcement in modifying anorexia nervosa. Behav Res Ther. 1968;6(2):211-8.

53. Nygaard JA. Anorexia nervosa. Treatment and triggering factors. Acta Psychiatr Scand Suppl. 1990;361:44-9.

54. Pertschuk M, Edwards N, Pomerleau O. A multiple-baseline approach to Behavioural intervention in anorexia nervosa. Behav Ther. 1978;9:368-76.

55. Poole AD, Sanson-Fisher RW, Young P. A behavioural programme for the management of anorexia nervosa. Aust N Z J Psychiatry. 1978;12(1):49-53.

56. Solanto MV, Jacobson MS, Heller L, Golden NH, Hertz S. Rate of weight gain of inpatients with anorexia nervosa under two behavioral contracts. Pediatrics. 1994;93(6 Pt 1):989-91.

57. Steinhausen HC. Evaluation of inpatient treatment of adolescent anorexic patients. J Psychiatr Res. 1985;19(2-3):371-5.

58. Groen JJ, Feldman-Toledano Z. Educative treatment of patients and parentsin anorexia nervosa. Br J Psychiatry. 1966;112(488):671-81.

59. Kronenberg J, Nachshoni T, Neumann M, Gaoni B. The treatment of anorexia-nervosa in a general-hospital - a case vignette of a multidisciplinary general hospital-based approach. J Adolesc. 1994;17(2): $163-71$.

60. Jenkins ME. An outcome study of anorexia nervosa in an adolescent unit. J Adolesc. 1987;10(1):71-81.

61. Maxmen JS, Siberfarb PM, Ferrell RB. Anorexia nervosa. Practical initial management in a general hospital. JAMA. 1974;229(7):801-3.

62. Wockel L, Zepf FD, Koch S, Meyer-Keitel AE, Schmidt MH. Serotonin-induced decrease of intracellular $\mathrm{ca}(2+)$ release in platelets of bulimic patients normalizes during treatment. J Neural Transm (Vienna). 2009;116(1):89-95.

63. Spettigue W, Norris ML, Santos A, Obeid N. Treatment of children and adolescents with avoidant/restrictive food intake disorder: a case series examining the feasibility of family therapy and adjunctive treatments. J Eat Disord. 2018;6:20.
64. Singer L, Ambuel B, Wade S, Jaffe A. Cognitive-Behavioural treatment of health-impairing food phobias in children. J Am Acad Child Adolesc Psychiatry. 1992;31(5):847-52.

65. Pitt PD, Middleman AB. A focus on behavior Management of Avoidant/ restrictive food intake disorder (ARFID): a case series. Clin Pediatr (Phila). 2018;57(4):478-80

66. Dalle Grave R, Calugi S, El Ghoch M, Conti M, Fairburn CG. Inpatient cognitive behavior therapy for adolescents with anorexia nervosa: immediate and longer-term effects. Front Psychiatry. 2014;5:14:1-7. https:// doi.org/10.3389/fpsyt.2014.00014.

67. El Ghoch M, Milanese C, Calugi S, Muller MJ, Pourhassan M, Ruocco A, et al. Regional fat distribution in adolescent and adult females with anorexia nervosa: a longitudinal study. Clin Nutr. 2014;34(6):P1224-32. https://doi.org/ 10.1016/j.clnu.2014.12.012.

68. Hillen S, Dempfle A, Seitz J, Herpertz-Dahlmann B, Buhren K. Motivation to change and perceptions of the admission process with respect to outcome in adolescent anorexia nervosa. BMC Psychiatry. 2015;15:140.

69. Strober M, Freeman R, Lampert C, Diamond J, Teplinsky C, DeAntonio M. Are there gender differences in core symptoms, temperament, and shortterm prospective outcome in anorexia nervosa? Int J Eat Disord. 2006;39(7): 570-5.

70. Treat TA, McCabe EB, Gaskill JA, Marcus MD. Treatment of anorexia nervosa in a specialty care continuum. Int J Eat Disord. 2008;41(6):564-72.

71. Asch M, Esteves J, De Hautecloque D, Bargiacchi A, Le Heuzey MF, Mouren MC, et al. Cognitive remediation therapy for children and adolescents with anorexia nervosa in France: an exploratory study. Encephale. 2014;40(3):240-6.

72. Kuge R, Lang K, Yokota A, Kodama S, Morino Y, Nakazato M, et al. Group cognitive remediation therapy for younger adolescents with anorexia nervosa: a feasibility study in a Japanese sample. BMC Res Notes. 2017;10(1):317.

73. Harrison A, Stavri P, Ormond L, McEnemy F, Akyol D, Qureshi A, et al. Cognitive remediation therapy for adolescent inpatients with severe and complex anorexia nervosa: a treatment trial. Eur Eat Disord Rev. 2018;26(3): 230-40

74. Herbrich L, van Noort B, Pfeiffer E, Lehmkuhl U, Winter S, Kappel V. Followup assessment of cognitive remediation therapy in adolescent anorexia nervosa: a pilot study. Eur Eat Disord Rev. 2017;25(2):104-13.

75. Depestele L, Claes L, Dierckx E, Colman R, Schoevaerts K, Lemmens GMD. An adjunctive multi-family group intervention with or without patient participation during an inpatient treatment for adolescents with an eating disorder: a pilot study. Eur Eat Disord Rev. 2017;25(6):570-8.

76. Janas-Kozik M, Krzystanek M, Stachowicz M, Krupka-Matuszczyk I, Janas A, Rybakowski JK. Bright light treatment of depressive symptoms in patients with restrictive type of anorexia nervosa. J Affect Disord. 2011;130(3):462-5.

77. Couturier J, Mahmood A. Meal support therapy reduces the use of nasogastric feeding for adolescents hospitalized with anorexia nervosa. Eat Disord. 2009;17(4):327-32.

78. Kells M, Davidson K, Hitchko L, O'Neil K, Schubert-Bob P, McCabe M. Examining supervised meals in patients with restrictive eating disorders. Appl Nurs Res. 2013;26(2):76-9.

79. Kells M, Schubert-Bob P, Nagle K, Hitchko L, O'Neil K, Forbes P, et al. Meal supervision during medical hospitalization for eating disorders. Clin Nurs Res. 2016;26(4):525-37.

80. Leacy KA, Cane JN. Effect of non-select menus on weight and eating concern in adolescents hospitalized with anorexia nervosa. Eat Disord. 2012; 20(2):159-67.

\section{Publisher's Note}

Springer Nature remains neutral with regard to jurisdictional claims in published maps and institutional affiliations. 